\title{
Rapid modulation of hypothalamic Kiss1 levels by the suckling stimulus in the lactating rat
}

\section{Shimpei Higo, Satoko Aikawa, Norio lijima and Hitoshi Ozawa}

Department of Anatomy and Neurobiology, Graduate School of Medicine, Nippon Medical School, Sendagi 1-1-5, Bunkyo-ku, Tokyo 113-8602, Japan
Correspondence should be addressed to H Ozawa

Email hozawa@nms.ac.jp

\begin{abstract}
In mammals, lactation suppresses $\mathrm{GnRH} / \mathrm{LH}$ secretion resulting in transient infertility.

In rats, $\mathrm{GnRH} / \mathrm{LH}$ secretion is rescued within 18-48 $\mathrm{h}$ after pup separation (PS) and rapidly re-suppressed by subsequent re-exposure of pups. To elucidate the mechanisms underlying these rapid modulations, changes in the expression of kisspeptin, a stimulator of $\mathrm{GnRH}$ secretion, in several lactating conditions (normal-lactating; 4-h PS; 18-h PS; 4-h PS + 1-h re-exposure of pups; non-lactating) were examined using in situ hybridization. PS for $4 \mathrm{~h}$ or $18 \mathrm{~h}$ increased Kiss 1 expressing neurons in both the anteroventral periventricular nucleus (AVPV) and the arcuate nucleus (ARC), and subsequent exposure of pups re-suppressed Kiss 1 in the AVPV. A change in Kiss1 expression was observed prior to the reported time of the change in $\mathrm{GnRH} / \mathrm{LH}$, indicating that the change in $\mathrm{GnRH} / \mathrm{LH}$ results from changes in kisspeptin. We further examined the mechanisms underlying the rapid modulation of Kiss 1. We first investigated the possible involvement of ascending sensory input during the suckling stimulus. Injection of the anterograde tracer to the subparafascicular parvocellular nucleus (SPFPc) in the midbrain, which relays the suckling stimulus, revealed direct neuronal connections between the SPFpc and kisspeptin neurons in both the AVPV and ARC. We also examined the possible involvement of prolactin (PRL). Administration of PRL for $1 \mathrm{~h}$ suppressed Kiss 1 expression in the AVPV but not in the ARC. These results indicate that suckling stimulus rapidly modulates Kiss 1 expression directly via neuronal connections and indirectly through serum $\mathrm{PRL}$, resulting in modulation in $\mathrm{GnRH} / \mathrm{LH}$ secretion.
\end{abstract}

Key Words

- reproduction

- gonadotrophin releasing hormone

$\checkmark$ PRL

\section{Introduction}

Lactation suppresses ovulation resulting in transient infertility in various mammals including humans (McNeilly 2001). Lactation-induced infertility is characterized by a decrease in GnRH secretion from the hypothalamus, and a consequent decrease of luteinizing hormone (LH) secretion from the pituitary (Smith \& Neill 1977, Fox \& Smith 1984, Maeda et al. 1987). Several studies indicate that LH secretion is dynamically modified along with the modulation of the suckling stimulus in a rapid manner. In rats, Maeda et al. (1989) showed that lactation-induced decreases in GnRH/LH secretion are rescued in 18-48 h after pup separation (PS) and are rapidly re-suppressed by subsequent re-exposure of pups. Li et al. (1998) also reported the increase of plasma LH by 48-h PS and re-suppression by 24-h re-exposure of pups and Fukushima et al. (2006) showed that estrogen responsiveness of LH secretion was restored within $6 \mathrm{~h}$ after PS. Although these studies suggest that the proximal

Published by Bioscientifica Ltd 
cause of these rapid changes in $\mathrm{GnRH} / \mathrm{LH}$ secretion is the suckling stimulus, the neuroendocrine mechanisms linking the modulation in suckling stimulus and the change in GnRH/LH secretion are not yet fully understood.

Recent studies have shown that kisspeptin, a product of the Kiss1 gene, plays an important role in regulating $\mathrm{GnRH} / \mathrm{LH}$ secretion via activation of the G-protein coupled receptor 54 (GPR-54) in various animals (Kotani et al. 2001). In rodents, there are two discrete subpopulations of kisspeptin immunoreactive neurons with different physiological functions; the anteroventral periventricular nucleus (AVPV) and the arcuate nucleus (ARC) in the hypothalamus. With regard to its physiological function, kisspeptin neurons in the AVPV and ARC are responsible for the generation of surge and pulse patterns in GnRH/LH secretion respectively (Smith et al. 2006a, Li et al. 2009). In non-pregnant and non-lactating rodents, kisspeptin in the AVPV and ARC are regulated by estrogen in an opposite manner. In particular, kisspeptin neurons in the AVPV are positively regulated by estradiol, and those in the ARC are negatively regulated (Adachi et al. 2007, Smith 2008).

Several studies indicate the importance of kisspeptin systems in the lactation-induced suppression of GnRH/LH secretion (True et al. 2011, Yamada et al. 2012, AraujoLopes et al. 2014, Liu et al. 2014). For example, Kiss1 mRNA and kisspeptin peptide are reduced in the AVPV and ARC of lactating mice compared with non-lactating mice (Liu et al. 2014). In ovariectomized (OVX) rats, lactation induces the suppression of Kiss1 mRNA expression in the ARC, and reduced responsiveness of kisspeptin synthesis to estradiol in the AVPV (Yamada et al. 2007, 2012). However, despite these studies, information about kisspeptin synthesis following modification of the suckling stimulus (PS and re-suckling condition) remains incomplete.

The aim of this study is to clarify whether the change in kisspeptin system underlies the rapid change of $\mathrm{LH}$ secretion after the modification of suckling conditions, and to investigate the cellular mechanisms of the change. We examined the change in both Kiss 1 mRNA and the kisspeptin peptide in lactating rats under PS and resuckling conditions using in situ hybridization and immunohistochemstry. We also investigated possible mechanisms linking the suckling stimulus and Kiss1 mRNA expression. We first showed significant changes in Kiss1 mRNA expression in the AVPV and the ARC along with manipulation of lactating conditions. Second, we showed direct neuronal connections between the subparafascicular parvocellular nucleus (SPFpc), which is responsible for relaying the suckling stimulus and kisspeptin neurons in both the AVPV and the ARC using a anterograde tracing combined with immunohistochemistry against kisspeptin. Finally, we examined the involvement of serum prolactin (PRL) on the change in Kiss1 mRNA expression.

\section{Materials and methods}

\section{Animals}

Pregnant Wistar rats and 10-week-old female Wistar rats were purchased from Tokyo Laboratory Animals Science (Tokyo, Japan). Pregnant rats were mated between 8 and 10 weeks of age. Rats were housed on a $14 \mathrm{~h}$ light:10 h darkness cycle (light on from 0600 to $2000 \mathrm{~h}$ ), with unrestricted access to food and water. All experiments were performed in accordance with the institutional guidelines for the use of experimental animals and were approved by the Ethics Committee of Nippon Medical School.

\section{Manipulation of lactation condition}

The day newborn pups were discovered before noon was designated day 0 of lactation. The litter size was adjusted to 8 on day 1 . Some rats were separated from their pups in the afternoon of day 0 and served as non-lactating controls. Maeda et al. (1989) reported that LH secretion took at least $12 \mathrm{~h}$ to recover after PS, and that $6 \mathrm{~h}$ PS was insufficient for recovery. In this study, we used a short $4 \mathrm{~h}$ PS protocol in addition to $18 \mathrm{~h}$ PS, to clarify whether the change in kisspeptin preceded the recovery of LH secretion. Pregnant dams were separated into five groups: normal lactating $(n=8)$; PS for $4 \mathrm{~h}$ before sampling $(n=6)$; PS for $4 \mathrm{~h}$ followed by re-suckling for $1 \mathrm{~h}(n=5)$; PS for $18 \mathrm{~h}$ $(n=6)$; non-lactating control $(n=7)$. Cytology of vaginal smears was examined from day 4 until the day of sampling. Brain and blood sampling was performed between 1100 and $1400 \mathrm{~h}$ on day 8 . Lactating conditions and the timeline of sampling are summarized in Fig. 1.

\section{In situ hybridization}

Rats were deeply anesthetized with sodium pentobarbital $(50 \mathrm{mg} / \mathrm{kg}$, intraperitoneally) and transcardially perfused with $50 \mathrm{ml}$ of saline followed by $200 \mathrm{ml}$ of fixative containing $4 \%(\mathrm{w} / \mathrm{v})$ paraformaldehyde (PFA) in $0.1 \mathrm{M}$ phosphate buffer (PB, pH 7.4). Brains were quickly removed and postfixed in the same fixative for $24 \mathrm{~h}$ at $4{ }^{\circ} \mathrm{C}$, and transferred into PBS $(0.1 \mathrm{M} \mathrm{PB}, 0.9 \%(\mathrm{w} / \mathrm{v}) \mathrm{NaCl}$,

Published by Bioscientifica Ltd. 


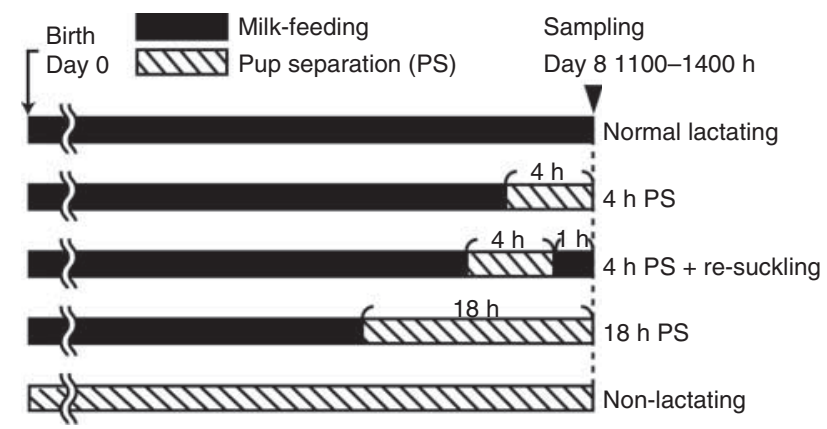

Figure 1

Experimental conditions and sampling. Lactating conditions and time of sampling are indicated in the figure. Black bars and hatched bars indicate normal lactation conditions and pup-separated conditions respectively.

pH 7.4) containing $20 \%(\mathrm{w} / \mathrm{v})$ sucrose for cryoprotection. Four series of serial coronal sections at $30-\mu \mathrm{m}$ thickness were cut using a cryostat (Leica 3050, Heidelberg, Germany), and collected into diethylpyrocarbonate (DEPC)-treated PBS. One series of sections containing seven sections of the AVPV (approx. AP 0.15 to $-0.60 \mathrm{~mm}$ from Bregma), and 16 or 17 sections of the ARC (approx. $\mathrm{AP}-1.70$ to $-4.00 \mathrm{~mm}$ from Bregma) were used. Sections were treated with $1 \mu \mathrm{g} / \mathrm{ml}$ proteinase $\mathrm{K}$ (Takara Bio, Inc., Otsu, Japan) in $10 \mathrm{mM}$ Tris buffer (pH 7.4) and $10 \mathrm{mM}$ EDTA for $15 \mathrm{~min}$ at $37^{\circ} \mathrm{C}$. After two washes in PBS, sections were incubated with $0.25 \%(\mathrm{v} / \mathrm{v})$ acetic anhydride in $0.1 \mathrm{M}$ triethanolamine for $20 \mathrm{~min}$ at room temperature. After the prehybridization treatment in prehybridization buffer $(1 \times$ hybridization solution (Sigma-Aldrich) containing $50 \%(\mathrm{v} / \mathrm{v})$ formamide and $10 \%(\mathrm{w} / \mathrm{v})$ dextran sulfate), sections were hybridized with $1 \mathrm{ng} / \mathrm{ml}$ digoxigenin (DIG)-labeled RNA probes for Kiss1 diluted in prehybridization buffer for $16 \mathrm{~h}$ at $60^{\circ} \mathrm{C}$. Anti-sense and sense RNA probes were synthesized from template cDNA of rat full-length rat Kiss1 (GeneBank accession \#AY196983) (Terao et al. 2004) using a DIG-RNA labeling kit (Roche Diagnostics). After hybridization, sections were rinsed in $4 \times$ saline sodium sitrate (SSC) containing 50\% formamide followed by $2 \times \mathrm{SSC}$ for $20 \mathrm{~min}$ at $60^{\circ} \mathrm{C}$, and treated with RNaseA $(20 \mu \mathrm{g} / \mathrm{ml}$ in $10 \mathrm{mM}$ Tris- $\mathrm{HCl}$ (pH 8.0), $1 \mathrm{mM}$ EDTA, and $500 \mathrm{nM} \mathrm{NaCl}$ ) for $20 \mathrm{~min}$ at $37^{\circ} \mathrm{C}$. Sections were then washed under conditions of increasing stringency. DIG-labeled RNA probes were visualized using standard immunohistochemical procedures with the alkaline phosphatase conjugated anti-DIG antibody (Roche Diagnostics) and chromogen solution containing nitro blue tetrazolium and 5-Bromo-4-chloro-3-indolyl phosphate (NBT/BCIP, Roche Diagnostics) in Tris-HCl buffered saline ( $\mathrm{pH}$ 9.5). Color development was performed in a dark box for $3 \mathrm{~h}$ at $25^{\circ} \mathrm{C}$, and was ceased by several washes in PBS. Images of each section ware acquired using a BX-51 microscope (Olympus). Kiss1 mRNA expressing neurons in each section were counted using ImageJ (v1.47, NIH, USA) with the Cell Counter plugin.

\section{Immunohistochemistry}

Immunohistochemistry against kisspeptin was performed using a streptavidin-HRP based kit (Histofine SAB-PO kit, Nichirei Corporation, Tokyo, Japan). A series of coronal sections from each animal (seven sections of the AVPV, and 16 or 17 sections of the ARC) were treated with $0.03 \%$ (v/v) $\mathrm{H}_{2} \mathrm{O}_{2}$ in $\mathrm{PBS}$ to quench endogenous peroxidase activity, and then washed three times in PBS. After blocking in $5 \%(\mathrm{v} / \mathrm{v})$ normal rabbit serum, sections were immersed in anti-kisspeptin monoclonal antibody (a kind gift from Takeda Pharmaceutical Co. Ltd, Tokyo, Japan) solution at a dilution of 1:2000 in PBS and incubated for $48 \mathrm{~h}$ at $4{ }^{\circ} \mathrm{C}$. The specificity of the antibody was reported previously (Kinoshita et al. 2005). Kisspeptin neurons were visualized broadly following the protocol supplied by the manufacturer of the Histofine kit as described in our previous research (Iijima et al. 2011). Kisspeptin visualization was achieved with diaminobenzidine (DAB; DAKO, Inc., Carpinteria, CA, USA). Kisspeptin-positive neurons in each section were counted using ImageJ.

\section{Anterograde tracer injection and immunohistochemistry}

Injection of the primary anterograde tracer biotinylated dextran amine (BDA, MW 10 000, Life Technologies) was performed according to Szabo et al. (2010) with slight modification using a stereotaxic instrument (SR-5R, Narishige, Tokyo, Japan). Rats were anesthetized with $2.5 \%(\mathrm{v} / \mathrm{v})$ isoflurane during stereotaxic surgery. A $0.05 \mu \mathrm{l}$ of $5 \%(\mathrm{w} / \mathrm{v}) \mathrm{BDA}$ in saline was injected unilaterally into the SPFpc by pressure through a glass micropipette attached to a Picospritzer III (General Valve Corporation, Fairfield, NJ, USA), using the following coordinates; AP - 4.9; ML 2.7 in relation to bregma; DV 6.9 from skull surface. Forty-eight hours after BDA injection, colchicine $(50 \mu \mathrm{g} / 10 \mu \mathrm{l}$ saline, Wako Chemicals, Tokyo, Japan) was administered intracerebroventricularly (stereotaxic coordinates: AP -1.2 ; ML 2.2, DV 3.6) to enhance the immunoreactivity for the kisspeptin, using a Hamilton syringe $(10 \mu \mathrm{l})$. Twenty-four hours after colchicine injection, rats were perfusion fixed using fixative containing $4 \%(\mathrm{w} / \mathrm{v}) \mathrm{PFA}$, and $0.25 \%(\mathrm{w} / \mathrm{v})$ glutaraldehyde in $0.1 \mathrm{M}$ PB. Brains were postfixed in $4 \%$ PFA for $24 \mathrm{~h}$ at $4{ }^{\circ} \mathrm{C}$ and

Published by Bioscientifica Ltd. 
cryoprotected in PBS containing 20\% (w/v) sucrose. Serial coronal sections at $30-\mu \mathrm{m}$ thickness were cut using a cryostat, and collected into PBS. Simultaneous visualization of BDA-positive projections and kisspeptin neurons was performed using a Histofine SAB-PO kit (Nichirei Corporation). After quenching endogenous peroxidase in $0.03 \%(\mathrm{v} / \mathrm{v}) \mathrm{H}_{2} \mathrm{O}_{2}$, sections were incubated in streptavidin-HRP solution (Histofine SAB-PO kit) for $1 \mathrm{~h}$ at room temperature. After washing in PBS, BDA was visualized using a chromogen solution containing DAB, nickel sulfite, and cobalt chloride with $\mathrm{H}_{2} \mathrm{O}_{2}$ in $0.05 \mathrm{M}$ Tris- $\mathrm{HCl}$ buffer ( $\mathrm{pH}$ 7.5). After quenching residual HRP activity in $0.3 \%(\mathrm{v} / \mathrm{v}) \mathrm{H}_{2} \mathrm{O}_{2}$, normal immunohistochemical procedures were performed as previously described, with $\mathrm{DAB}$ as a chromogen. Images of each section were acquired using a BX-51 microscope (Olympus). We used $10 \times, 20 \times$, and oil immersion $100 \times$ objective lenses for acquisition of low-, medium-, and high-magnification images respectively. Only those animals in which the injection site was located in the targeted areas (four animals, two parous and two non-parous) were included in the results.

\section{Prolactin assay}

Blood samples were collected from the right ventricle of the heart just before perfusion under sodium pentobarbital anesthesia $(50 \mathrm{mg} / \mathrm{kg}$, intraperitoneally) and mixed with aprotinin (Takara Bio) at a final concentration of $50 \mu \mathrm{g} / \mathrm{ml}$. Blood collection of was performed within 4-6 min after pentobarbital injection. PRL levels were measured using a rat PRL ELISA Kit (CUSABIO, Hubei, China). After incubation for $30 \mathrm{~min}$ at room temperature, blood samples were centrifuged at $1600 \boldsymbol{g}$ for $15 \mathrm{~min}$ at $4{ }^{\circ} \mathrm{C}$, and the supernatant was collected in plastic tubes. All the samples were stored at $-80^{\circ} \mathrm{C}$ and assayed simultaneously. The hormone concentrations in each sample were assessed according to the manufacture's specifications. A calibration curve was calculated according to the Rodbard model (DeLean et al. 1978). Samples were diluted $1 / 5$, and the assay was performed in duplicate.

\section{Continuous administration of PRL}

Two days before sampling, a catheter made of silicone rubber tubing (SILASCON 100N-00, Kaneka Medical Product, Osaka, Japan) was inserted through the right jugular vein into the right atrium of the lactating rat under anesthesia using $2.5 \%(\mathrm{v} / \mathrm{v})$ isoflurane. The catheter was filled with $40 \%(\mathrm{v} / \mathrm{v})$ polyvinylpyrrolidone in heparinized saline until PRL administration. Before sampling (18 h), PS and injection of bromocriptine (1 $\mathrm{mg} / \mathrm{kg}$, subcutaneously) were performed. PRL (ovine prolactin, Sigma-Aldrich) solution $(9.0 \mathrm{mg} / \mathrm{ml}$ in saline, $n=5)$ or saline (for control, $n=4$ ) was continuously administered through the catheter for $60 \mathrm{~min}$ at a flow rate of $1 \mu \mathrm{l} / \mathrm{min}$. The dose of PRL was comparable to that used in previous reports (Bridges \& Ronsheim 1990, Araujo-Lopes et al. 2014). Immediately after cessation of PRL administration, the rats were perfusion-fixed and sampled. Kiss 1 mRNA expression in each sample was assessed by in situ hybridization as previously described.

\section{Statistical analysis}

One-way ANOVA followed by the Tukey-Kramer post-hoc test was applied for the analysis of Kiss1 mRNA expression, kisspeptin immunoreactivity, and serum PRL concentrations in manipulated lactation conditions. The Students' $t$-test was performed for analysis of Kiss1 mRNA expression in continuous PRL administration. Statistical analyses were performed using IBM SPSS statistics software, with a $P$ value of $<0.05$ considered statistically significant.

\section{Results}

\section{Cytology of vaginal smears in lactating rats}

No ovarian cycle was observed in the cytology of the vaginal smears in normal lactating, 4-h PS, re-suckling after 4-h PS, and 18-h PS groups. The cytology of vaginal smears in all groups were displayed characteristics similar to those during diestrus. In non-lactating groups, although the cytology was relatively obscurer compared with normal diestrus rats, the vaginal cytology on the day of sampling from one rat was similar to that of proestrus, two were similar to that of estrus, and four were similar to that of diestrus.

\section{Change in Kiss 1 mRNA expression by manipulation of lactation conditions}

In each group, Kiss1 mRNA-expressing neurons were observed in both the AVPV and the ARC (Fig. 2A). Compared with non-lactating groups, normal lactating groups displayed significantly lower expression of Kiss 1 mRNA in both the AVPV and ARC. The numbers of Kiss1 mRNA-expressing neurons were significantly higher in the 4-h PS and 18-h PS groups compared with normal lactating (non-PS) controls (Fig. 2B) in both AVPV and ARC. The numbers of Kiss1 mRNA-expressing neurons in the AVPV

Published by Bioscientifica Ltd 
A
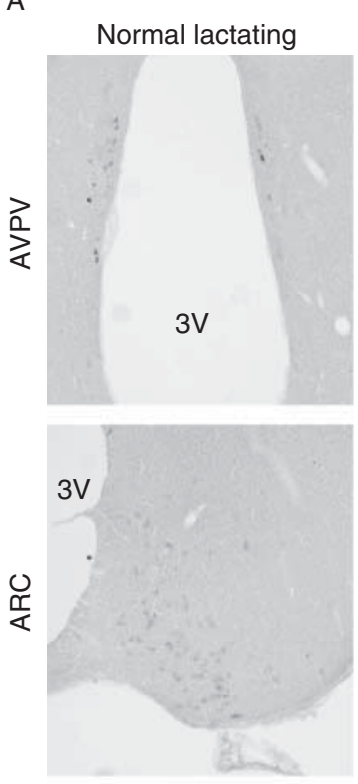

B AVPV
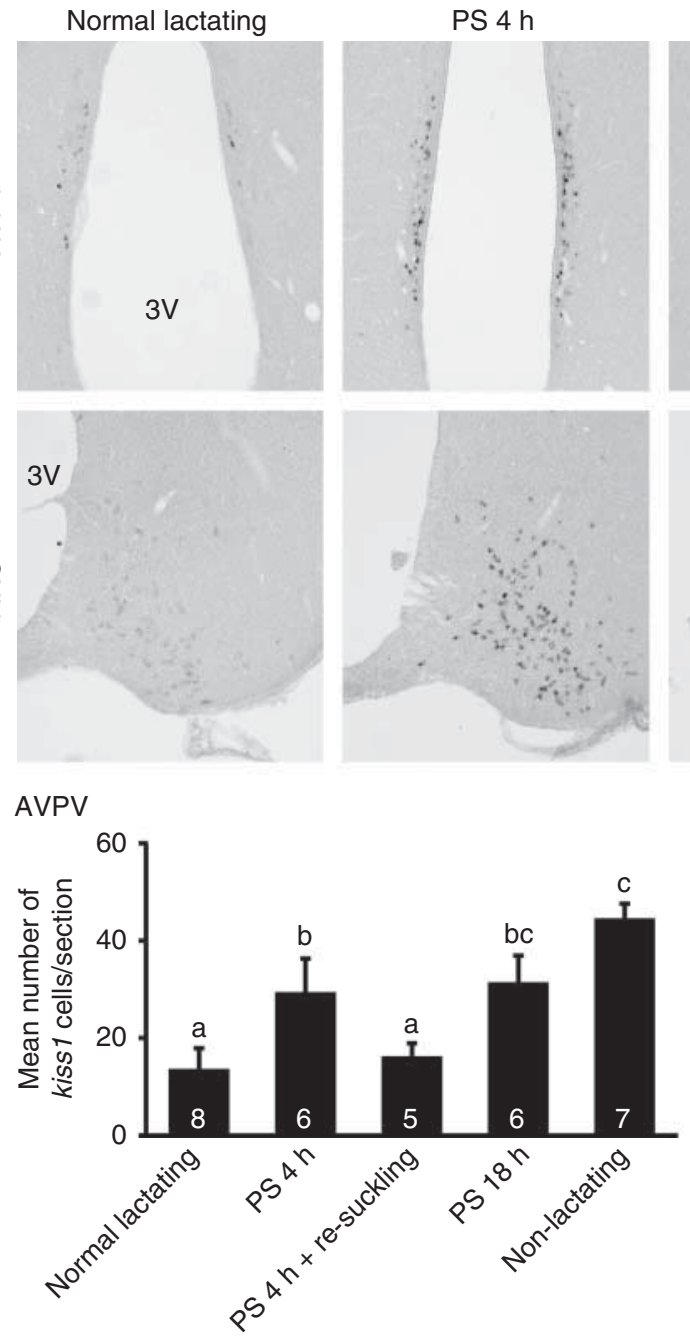

PS $4 \mathrm{~h}$ re-suckling $1 \mathrm{~h}$
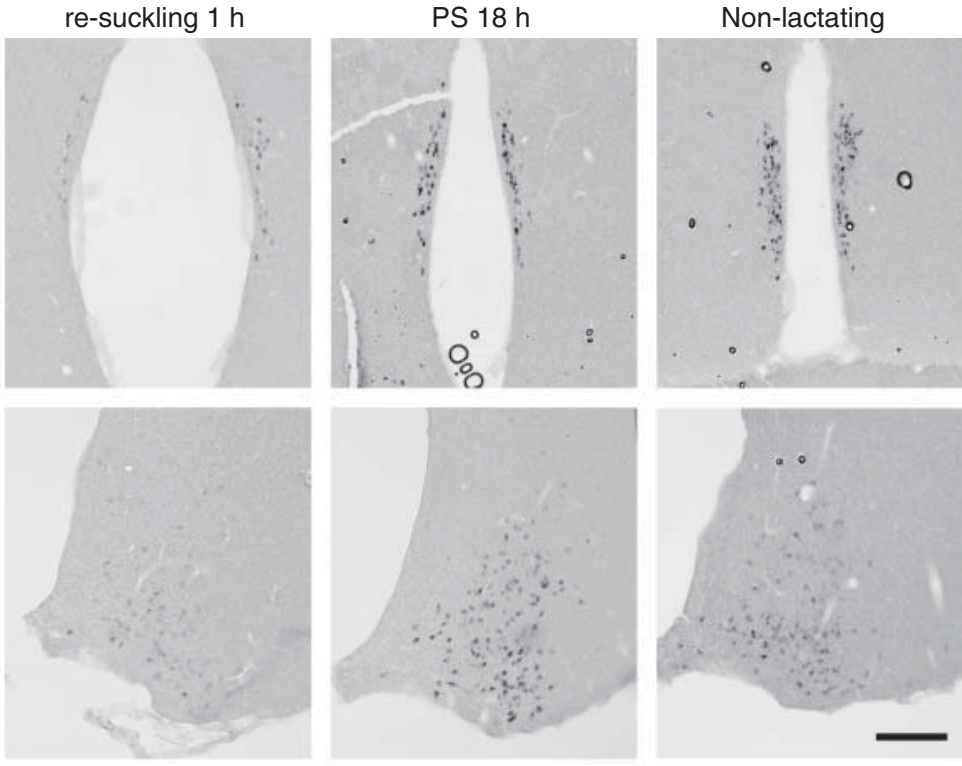

ARC

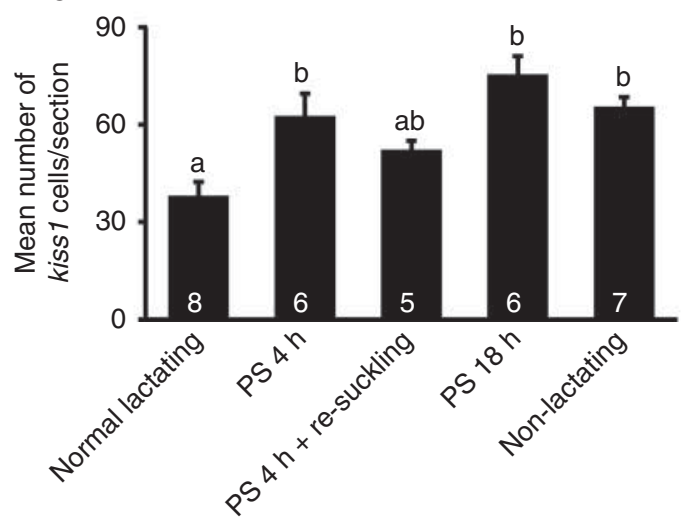

Figure 2

Change in Kiss1 mRNA-expressing neurons following manipulation in lactation conditions. (A) Representative images of Kiss1-positive neurons in the AVPV (upper column) and ARC (lower column). Scale bar; $100 \mu \mathrm{m}$. 3V; third ventricle. (B) Quantification of the Kiss1-positive neurons in the AVPV

were suppressed by 1-h re-suckling to a level comparable to that in normal lactating rats. In the ARC, the number of Kiss1 mRNA-expressing neurons in the 1-h re-suckling group was at a level intermediate between that of normal lactating and 4-h PS. The numbers of Kiss1 mRNAexpressing neurons in non-lactating groups were significantly higher than normal lactating controls.

\section{Changes in kisspeptin-immunoreactive neurons by manipulation of lactation conditions}

Kisspeptin-immunoreactive (kiss-ir) neurons were observed in both the AVPV and ARC (Fig. 3A and Printed in Great Britain and ARC. The numbers in the bar graphs represent the number of animals in each group. Same alphabetical annotation in $B$ denotes non-significant differences between groups (one-way ANOVA, $P<0.05$ ).

Supplementary Figure S1, see section on supplementary data given at the end of this article). The change in kiss-ir neurons was similar to that observed for Kiss1 mRNA expression, but less marked. Statistical significance was observed only between the normal lactating and 18-h RS groups in both the AVPV and the ARC (Fig. 3B).

\section{Afferent input to kisspeptin neurons from the SPFpc}

Previous studies on lactating animals have identified several neuronal populations or brain nuclei that respond to the suckling stimulus including some brainstem areas such as the peripeduncular nucleus, SPFpc, and caudal area

Published by Bioscientifica Ltd 
A
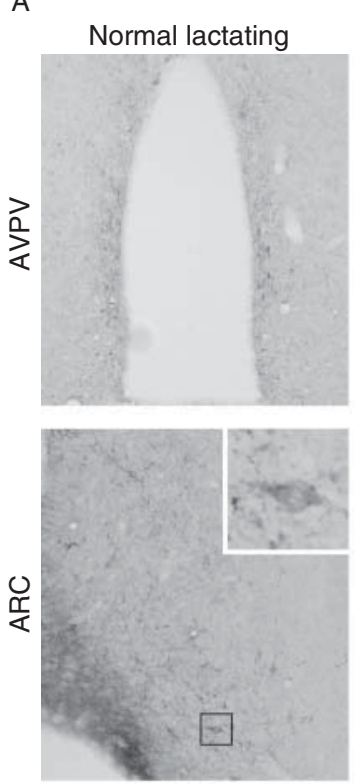

B AVPV
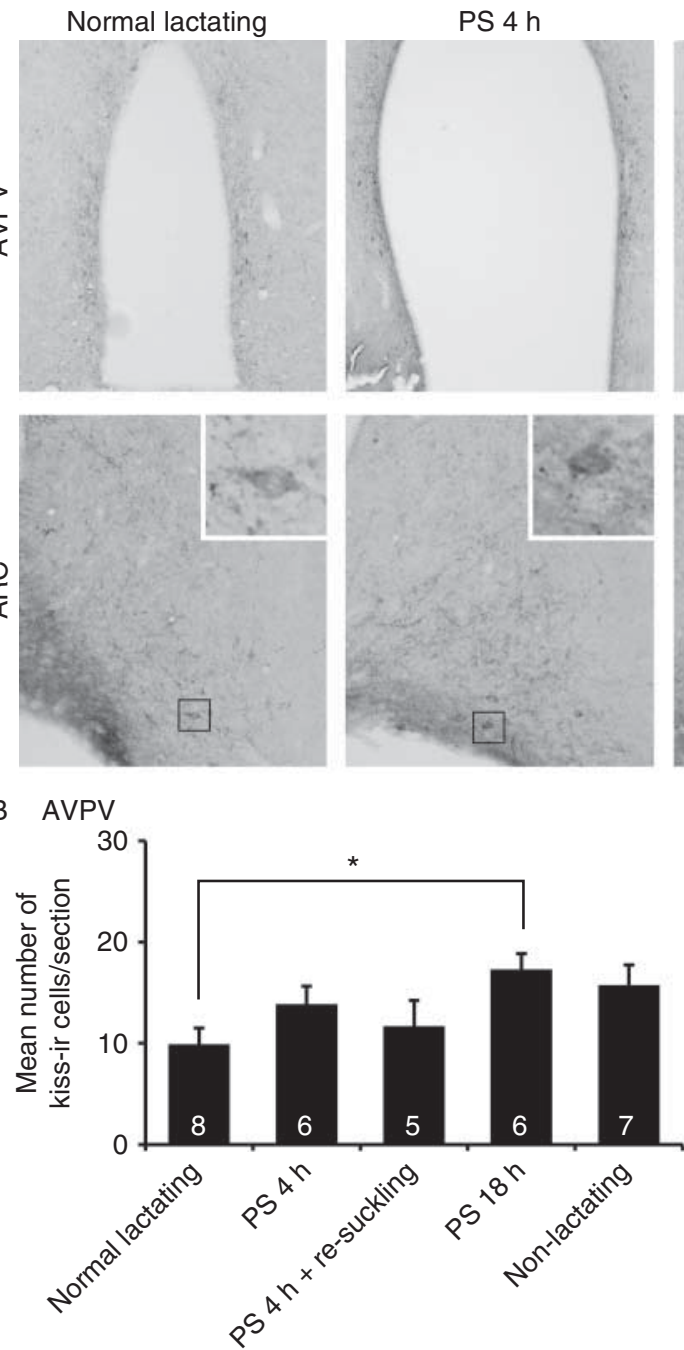

PS $4 \mathrm{~h}$ re-suckling $1 \mathrm{~h}$
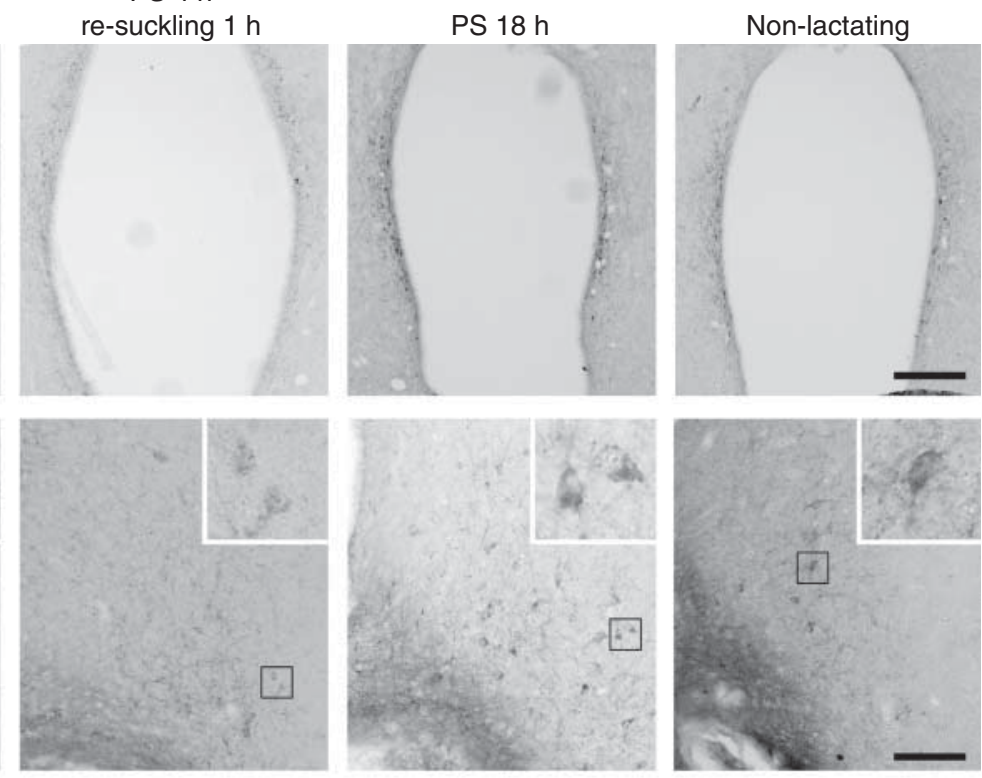

ARC

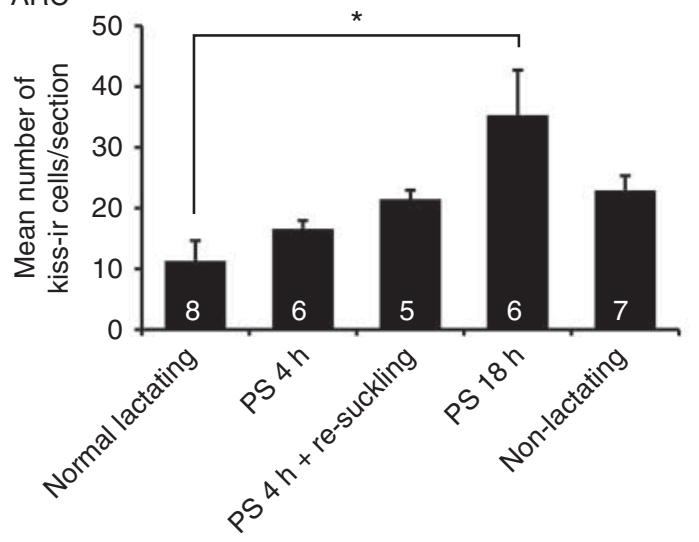

Figure 3

Change in kisspeptin-immunoreactive neurons following manipulation in lactation conditions. (A) Representative images of kiss-ir neurons in the AVPV (upper column) and ARC (lower column). Insets in the photomicrographs of the ARC show the magnified image of the cell bodies in the framed area of corresponding images. Scale bar; $100 \mu \mathrm{m}$ in the AVPV, $50 \mu \mathrm{m}$ in the ARC. 3V; third ventricle. (B) Quantification of the kissp-ir neurons in the AVPV and ARC. The numbers in the bar graphs represent the number of animals in each group. Asterisk denotes significant difference between groups (one-way ANOVA, $P<0.05$ ). of the periaqueductal gray (Li et al. 1999, Lonstein \& Stern 1999, Marina et al. 2002, Szabo et al. 2010). In this study, we focused on the SPFpc as a most probable candidate of the relay nucleus of the suckling stimuli to kisspeptin neurons, because the subpopulation of the neurons in the SPFpc has been reported to project fibers to neurons in the ARC (Szabo et al. 2010). To examine the possibility of direct neuronal connection between the SPFpc and kisspeptin neurons, anterograde tracer injection was performed (Fig. 4A). Projection fibers from the SPFpc were seen in both the AVPV (Fig. 4B, C, D, and E) and the
ARC (Fig. 4F, G, H, and I). In the AVPV, the majority of projection fibers were seen on the ipsilateral side of the injection area, and small amounts of labeled fibers were seen on the contralateral side, whereas the projection fibers in the ARC exclusively resided on the ipsilateral side. High-magnification photomicrographs showed projection fibers in close apposition to the cell bodies of kisspeptin neurons in both the AVPV (Fig. 4D and E) and ARC (Fig. 4G, $\mathrm{H}$, and I). Close apposition of the BDA-labeled fibers to the cell bodies were seen in all four animals used in the experiment in the ARC, and in three rats in the AVPV. 

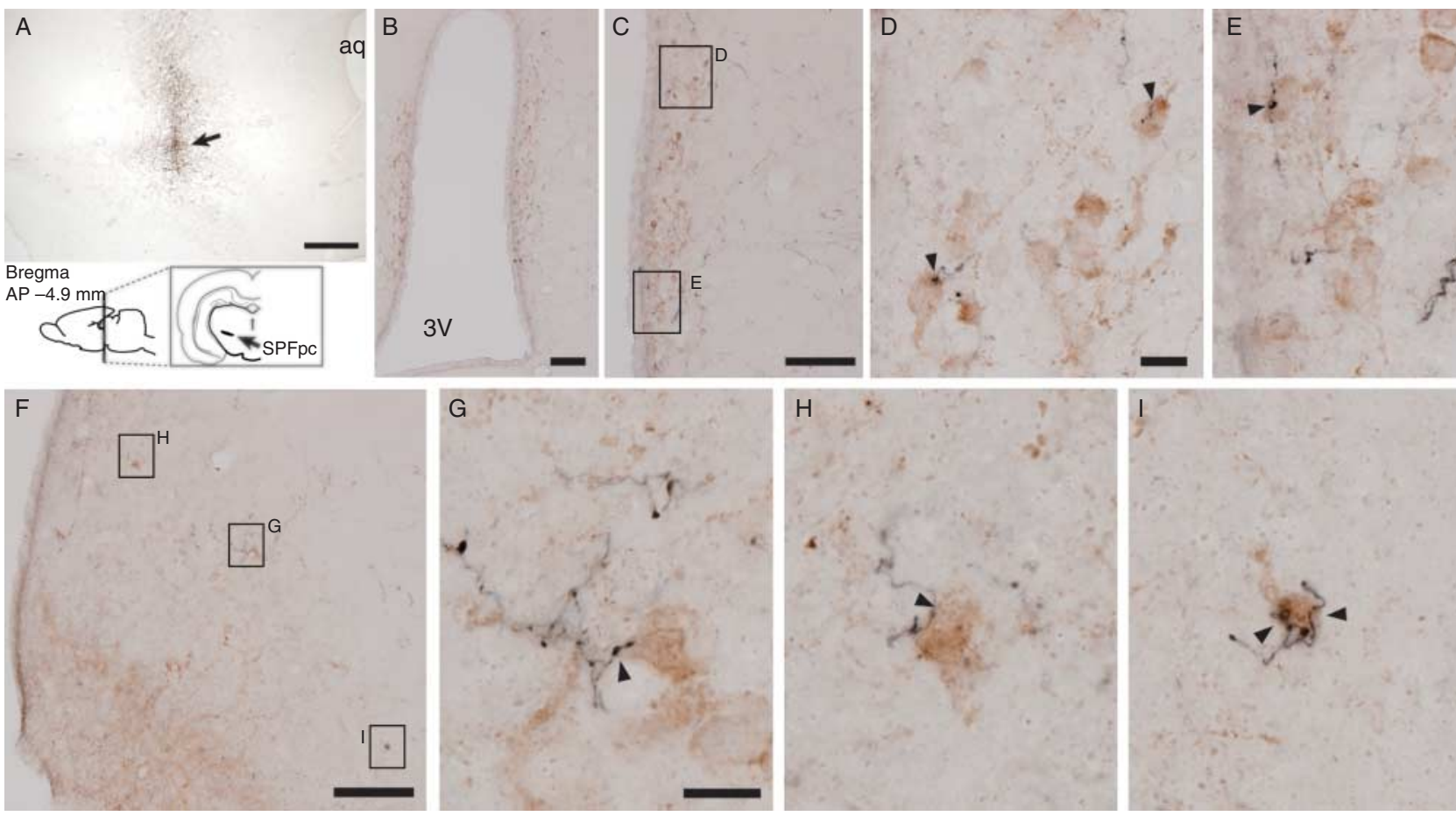

Figure 4

Simultaneous visualization of kisspeptin neurons and the projections from the SPFpc. Coronal sections of the brain were double-stained for kisspeptin (brown, DAB) and BDA (black fiber, nickel-cobalt DAB). (A) Upper panel shows a representative image of the BDA injection site including the SPFpC (black allow). Lower panel shows schematic illustration of transection of the midbrain containing SPFpc (AP $-4.9 \mathrm{~mm}$ from Bregma). aq; cerebral aqueduct. ( $B$ and $C$ ) Microphotograph of a section containing the AVPV shows kisspeptin-positive neurons and BDA fibers from the SPFpc. 3V; third

\section{Change in Kiss 1 mRNA expression following continuous administration of PRL}

Serum concentrations of PRL showed significant changes in association with the manipulation of lactating conditions (Fig. 5A). Serum PRL slightly decreased in the 4-h PS group compared with normal lactating controls. However, a significant increase in serum PRL was observed after 1-h re-suckling compared with 4-h PS. In nonlactating groups, serum concentrations of PRL were lower than that of normal lactating animals.

Kisspeptin expression in the AVPV and ARC after 1-h continuous PRL administration was assayed using in situ hybridization to examine the possible involvement of changes in serum PRL on re-suppression of Kiss1 mRNA expression (Fig. 5B). Female rats were pup deprived and treated with bromocriptine $18 \mathrm{~h}$ prior to PRL infusion to mimic suckling deprivation-induced Kiss1 mRNA upregulation and to ensure a low concentration of serum PRL. Kiss1 mRNA expression in saline-administered ventricle. ( $D$ and $E$ ) High-magnification images of the framed area in $C$. Microphotograph of a section containing the ARC is shown in I. (G, $H$, and I) High-magnification images of framed area in $\mathrm{F}$. BDA-labeled fibers were seen in close apposition to cell bodies of kisspeptin neurons in both the $\operatorname{AVPV}(B$ and $C$ ) and ARC ( $G, H$, and I) (black allow head). The rats used in the experiment ware treated with colchicine to enhance kiss-ir. Scale bars; $500 \mu \mathrm{m}$ for $\mathrm{A}, 100 \mu \mathrm{m}$ for $\mathrm{B}, \mathrm{C}$, and $\mathrm{F}, 10 \mu \mathrm{m}$ for $\mathrm{D}, \mathrm{E}, \mathrm{G}, \mathrm{H}$, and I.

control rats displayed levels comparable to that of 18 -h PS rats in the previous experiment. One-hour administration of PRL significantly suppressed Kiss 1 expression in the AVPV, but not in the ARC (Fig. 5B).

\section{Discussion}

In the present study, we investigated the change in Kiss1 mRNA expression and kisspeptin peptide following modulation of the suckling stimulus, and identified possible mechanisms mediating the suckling stimulus and Kiss1 mRNA expression. Our data provides evidence supporting a significant role of kisspeptin as a modulator of the acute change in LH secretion after modulation of the suckling stimulus reported in previous studies. Our results further indicate that the lactation-induced rapid modulations of kisspeptin are mediated by both direct neuronal input and serum PRL in the AVPV, and by direct neuronal input in the ARC.

Published by Bioscientifica Ltd 


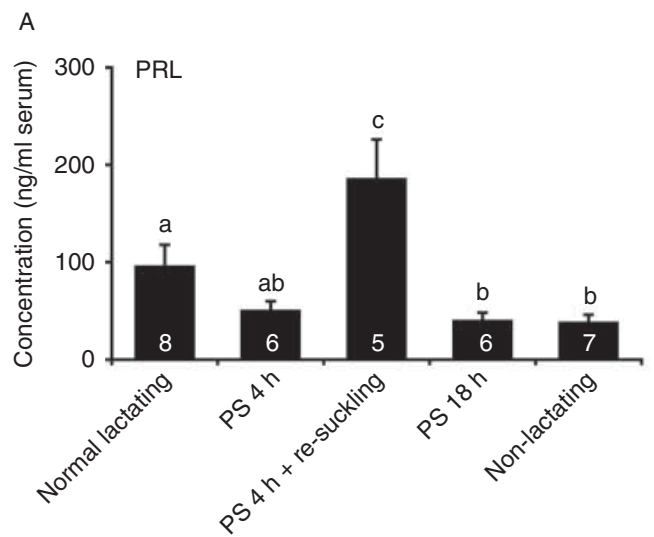

$\mathrm{B}$

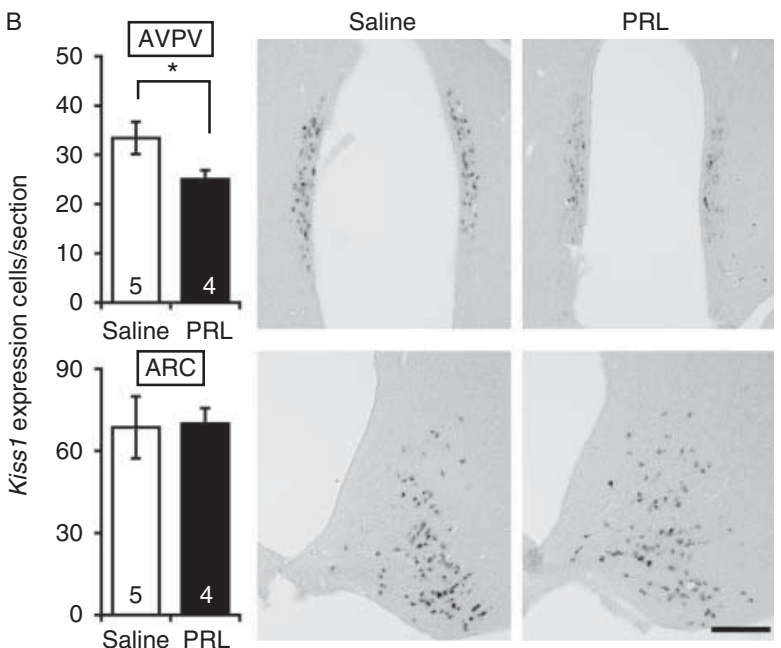

\section{Figure 5}

Kiss 1 mRNA expressions after $1 \mathrm{~h}$ continuous administration of prolactin. Serum concentrations of PRL under modified lactating conditions are shown in A. Same alphabetic annotation denotes non-significant difference between groups (one-way ANOVA, $P<0.05$ ). Representative images of Kiss 1 neurons in the AVPV and ARC after PRL administration and

Several studies report the reduced expression of kisspeptin under lactating condition using rats (Yamada et al. 2007, 2012, True et al. 2011, Araujo-Lopes et al. 2014) and mice (Liu et al. 2014). In this study, normal lactating rats showed reduced Kiss1 mRNA levels in the ARC in comparison with that of non-lactating animals, which is consistent with previous studies. Regarding the AVPV, controversial results have been reported in previous studies. Yamada et al. (2012) reported almost no detectable basal Kiss1 mRNA in OVX lactating rats, whereas True et al. (2011) reported a decrease in Kiss1 mRNA and an increase in kiss-ir neurons in intact lactating rats. In this study, reduced Kiss1 levels in the AVPV of gonadal intact lactating rats was largely consistent with that of True et al. (2011), indicating that the inconsistency in kisspeptin synthesis in the AVPV is mainly due to the effect of OVX. Although OVX rats are a good model to examine estrogen responsiveness and are widely used in lactating studies, the gonadal intact model reflects the native condition.

Our previous study, and several other studies, have reported that kiss-ir cell bodies in the AVPV of nonlactating rats are low or non-detectable (Iijima et al. 2011, Overgaard et al. 2013). However, in this study, kiss-ir cell bodies were detected in all the groups, even in the normal lactating group in which Kiss1 mRNA was suppressed. Detectable kiss-ir in the cell bodies in the AVPV was also

comparison of the number of Kiss1-positive neurons between PRL treated and control rats are shown in B. The numbers in the bar graphs represent the number of animals in each group. Scale bar; $100 \mu \mathrm{m}$. Asterisk denotes significant differences between groups (Students' $t$-test, $P<0.05$ ).

reported by True et al. (2011). True et al. also showed a lactation-induced decrease in kiss-ir cells in the ARC compared with intact diestrus controls. However, no significant change in kiss-ir between the lactation group and parous non-lactating group was observed in this study. These results indicate the possibility that lactation and birth experience suppresses the kisspeptin peptide release and/or axonal transport of kisspeptin. The numbers of the kiss-ir neurons are relatively smaller than that of Kiss1 mRNA expressing neurons observed in the in situ hybridization in all the experimental groups. It should be noted that such discrepancies between the Kiss 1 mRNA and the kisspeptin peptide have been reported in several studies (Iijima et al. 2011, Overgaard et al. 2013). These discrepancies could be due to the combination of several reasons including the turnover rate of the molecule, axonal transport of the peptide, and the accumulation in the neuronal cell bodies.

Taking into consideration the reported time-course of LH secretion after a change in suckling stimulus (12-48 h) (Maeda et al. 1989), a significant increase in kisspeptin in the 4-h PS group, and the subsequent decrease after 1-h resuckling in both the AVPV and ARC (Fig. 2) suggests that a rapid change in kisspeptin expression is a direct cause of the change in GnRH/LH secretion. Rapid changes in these models also provide evidence for the rapid turn-over rate of Kiss1 mRNA. The time-lag between the change in Kiss1

Published by Bioscientifica Ltd. 
and the recovery of LH secretion may be due to the time needed for the translation and accumulation of the kisspeptin peptide.

Because the change in kisspeptin after manipulation of the suckling condition is rapid, we first examined the direct neuronal modulation of kisspeptin neurons by the suckling stimulus. Recently, Szabo et al. (2010) reported that neuronal projections from the SPFpc, a relay nucleus of the suckling stimulus, innervate into the ARC. However, they did not clarify if the neurons receiving input from the SPFpc were kisspeptin neurons. Our present study provides evidence for a connection between the SPFpc and ARC. Several studies have identified various hormones that modulate the activity of kisspeptin neurons including estradiol, leptin, glucocorticoids and PRL (Smith et al. 2006b, Herbison 2008, Takumi et al. 2012, Araujo-Lopes et al. 2014). Electrophysiological studies also have identified several afferent neurotransmitters on kisspeptin, including glutamate, gamma aminobutyric acid (GABA), cocaine- and amphetamine-regulated transcript (CART), and neurokinin B (de Croft et al. 2013, True et al. 2013, Zhang et al. 2013). However, identification of the origin of the afferent projections on kisspeptin neurons are insufficient except for a study by Williams et al. (2011) reporting afferent input on AVPV kisspeptin neurons of vasopressin fibers from the suprachiasmatic nucleus. This limited understanding of the origins of afferent inputs on kisspeptin neurons may partially be because of the difficulty in applying conventional retrograde tracing experiments to the dispersed space distribution of kisspeptin neurons, particularly in the ARC. Anterograde tracing in this study discovered a new direct afferent pathway to kisspeptin neurons, from the SPFpc to kisspeptin neurons in both the AVPV and ARC. Brown et al. (2014) reported that elimination of sensory inputs from one side of the body by unilateral thelectomy did not affect kiss-ir cells in both the ipsilateral side and contralateral side of the AVPV. Small, but significant contralateral projections from the SPFpc to the AVPV were observed in this study, providing a possible explanation for their results. Although our study discovered the neuronal input to kisspeptin neurons, this may be a fraction of the total afferent pathway to kisspeptin neurons. Further investigation is needed to completely understand the importance of afferent input to kisspeptin neurons.

We next examined the possibility that serum PRL plays a role in rapid modulation of Kiss1 mRNA expression, because accumulating evidence suggests a relationship between the kisspeptin system and PRL secretion. Changes in serum PRL levels via modulation of lactating conditions were largely consistent with the idea that high serum concentrations of PRL are required for continued milk production (Mattheij et al. 1984). PRL receptor expression in kisspeptin neurons (Kokay et al. 2011, Li et al. 2011), and pSTAT5 expression in kisspeptin neurons after i.c.v. administration of PRL (Araujo-Lopes et al. 2014) indicates that kisspeptin neurons are responsive to PRL. Several studies report that PRL negatively modulates kisspeptin expression. Sonigo et al. (2012) reported reduced expression of kisspeptin in both the AVPV and ARC using chronically PRL-administered hyperprolactinemia model mice. Araujo-Lopes et al. (2014) also reported a reduction in kisspeptin in the ARC following daily injection of the PRL over 3 days in rats. Finally, Brown et al. (2014) reported reduced expression of Kiss1 in the AVPV of the PRL injected lactating. Although the difference in PRL levels between $4 \mathrm{~h}$ PS and nonlactating groups was non-significant, PRL levels showed a rough inverse relationship with Kiss1 expression in the AVPV, which was largely consistent with the idea that PRL has a suppressive effect on Kiss 1 expression. Additionally, reduced kisspeptin expression in the AVPV induced by $1 \mathrm{~h}$ administration of PRL indicated that kisspeptin responded more rapidly than previously reported.

Regarding Kiss1 expression in the ARC, changes in Kiss1 in the ARC after PS and re-suckling was less marked compared with that in the AVPV, and PRL administration did not have a significant effect on Kiss1 in the ARC. These results apparently contradict previous studies reporting clear changes in Kiss1 using long-term experimental paradigms. One plausible explanation is that the response of Kiss1 in the ARC to extrinsic modulators is slower than that of the AVPV, and consequently the change in Kiss1 in the ARC requires more time to reach statistical significance.

PRL secretion from the pituitary is negatively controlled by tuberoinfundibular dopaminergic (TIDA) neurons, and serum PRL levels remain low in the presence of dopamine from TIDA neurons in non-lactating and virgin animals (Gudelsky 1981). Suckling stimulus suppresses the expression of tyrosine hydroxylase, a key enzyme of dopamine production, in TIDA neurons, which results in the secretion of PRL from the pituitary (Berghorn et al. 2001). Recent studies have shown that kisspeptin neurons in the ARC directly project their axons to TIDA neurons (Sawai et al. 2012), and that kisspeptin suppresses the activity of TIDA neurons (Szawka et al. 2010). The afferent input from the SPFpc to kisspeptin neurons in the ARC observed in this study indicates a new regulatory mechanism of PRL secretion via a SPFpc-kisspeptin

Published by Bioscientifica Ltd. 
neuron-TIDA neuron feedback pathway. However, the physiological relevance of this pathway remains unclear, and is further complicated by the finding that kisspeptin expression is suppressed in lactating animals.

Because the lactation-induced suppression of the reproductive axis is an important adaptive system for offspring survival, intense research has been conducted to understand the molecular mechanisms of this suppression. Accumulating evidence has confirmed the importance of the kisspeptin system in the lactation-induced suppression of the reproductive axis. We provide here evidence that the rapid modulation of kisspeptin underlies suckling-induced changes in GnRH/LH secretion. The current study provides further morphological evidence of afferent neuronal input to kisspeptin neurons from the SPFpc, a relay nucleus of the suckling stimulus. The rapid change to the kisspeptin system may be mediated by afferent sensory input via the SPFpc-kisspeptin neuron pathway, and also partially by serum concentrations of PRL.

\section{Supplementary data}

This is linked to the online version of the paper at http://dx.doi.org/10.1530/ JOE-15-0143.

\section{Declaration of interest}

The authors declare that there is no conflict of interest that could be perceived as prejudicing the impartiality of the research reported.

\section{Funding}

This study was supported by the Japan Society for the Promotion of Science (JSPS) KAKENHI (Grants-in-Aid for Scientific Research, grant number $15 \mathrm{~K} 20062$ to $\mathrm{S} \mathrm{H}, 26460323$ to $\mathrm{H} \mathrm{O}$ and 26670115 to N I). The funders had no role in study design, data collection and analysis, decision to publish, or preparation of the manuscript.

\section{Author contribution statement}

$\mathrm{S} \mathrm{H}, \mathrm{S} \mathrm{A}$, and $\mathrm{H} \mathrm{O}$ conceived and designed the experiments. S $\mathrm{H}$ and $\mathrm{S} \mathrm{A}$ performed the experiments and analyzed the data. $\mathrm{S} \mathrm{H}, \mathrm{N} \mathrm{I}$, and $\mathrm{H} \mathrm{O}$ wrote the paper.

\section{Acknowledgements}

We are grateful to Takeda Pharmaceutical Co. Ltd for providing a plasmid containing full-length CDNA of rat Kiss1 for RNA probe synthesis, and providing a monoclonal antibody for kisspeptin.

\section{References}

Adachi S, Yamada S, Takatsu Y, Matsui H, Kinoshita M, Takase K, Sugiura H, Ohtaki T, Matsumoto H, Uenoyama Y et al. 2007 Involvement of anteroventral periventricular metastin/kisspeptin neurons in estrogen positive feedback action on luteinizing hormone release in female rats. Journal of Reproduction and Development 53 367-378. (doi:10.1262/jrd. 18146)

Araujo-Lopes R, Crampton JR, Aquino NS, Miranda RM, Kokay IC, Reis AM, Franci CR, Grattan DR \& Szawka RE 2014 Prolactin regulates kisspeptin neurons in the arcuate nucleus to suppress LH secretion in female rats. Endocrinology 155 1010-1020. (doi:10.1210/en.2013-1889)

Berghorn KA, Le WW, Sherman TG \& Hoffman GE 2001 Suckling stimulus suppresses messenger RNA for tyrosine hydroxylase in arcuate neurons during lactation. Journal of Comparative Neurology 438 423-432. (doi:10.1002/cne.1325)

Bridges RS \& Ronsheim PM 1990 Prolactin (PRL) regulation of maternal behavior in rats: bromocriptine treatment delays and PRL promotes the rapid onset of behavior. Endocrinology 126 837-848. (doi:10.1210/endo126-2-837)

Brown R, Herbison A \& Grattan D 2014 Prolactin regulation of kisspeptin neurons in the mouse brain and its role in the lactation-induced suppression of kisspeptin expression. Journal of Neuroendocrinology $\mathbf{2 6}$ 898-908. (doi:10.1111/jne.12223)

de Croft S, Boehm U \& Herbison AE 2013 Neurokinin B activates arcuate kisspeptin neurons through multiple tachykinin receptors in the male mouse. Endocrinology 154 2750-2760. (doi:10.1210/en.2013-1231)

DeLean A, Munson PJ \& Rodbard D 1978 Simultaneous analysis of families of sigmoidal curves: application to bioassay, radioligand assay, and physiological dose-response curves. American Journal of Physiology $\mathbf{2 3 5}$ E97-102.

Fox SR \& Smith MS 1984 The suppression of pulsatile luteinizing hormone secretion during lactation in the rat. Endocrinology 115 2045-2051. (doi:10.1210/endo-115-6-2045)

Fukushima A, Yin P, Ishida M, Sugiyama N \& Arita J 2006 Pup removal suppresses estrogen-induced surges of LH secretion and activation of GnRH neurons in lactating rats. Journal of Endocrinology 191 339-348. (doi:10.1677/joe.1.06728)

Gudelsky GA 1981 Tuberoinfundibular dopamine neurons and the regulation of prolactin secretion. Psychoneuroendocrinology 6 3-16. (doi:10.1016/0306-4530(81)90044-5)

Herbison AE 2008 Estrogen positive feedback to gonadotropin-releasing hormone (GnRH) neurons in the rodent: the case for the rostral periventricular area of the third ventricle (RP3V). Brain Research Reviews 57 277-287. (doi:10.1016/j.brainresrev.2007.05.006)

Iijima N, Takumi K, Sawai N \& Ozawa H 2011 An immunohistochemical study on the expressional dynamics of kisspeptin neurons relevant to GnRH neurons using a newly developed anti-kisspeptin antibody. Journal of Molecular Neuroscience 43 146-154. (doi:10.1007/s12031-0109433-y)

Kinoshita M, Tsukamura H, Adachi S, Matsui H, Uenoyama Y, Iwata K, Yamada S, Inoue K, Ohtaki T, Matsumoto H et al. 2005 Involvement of central metastin in the regulation of preovulatory luteinizing hormone surge and estrous cyclicity in female rats. Endocrinology 146 4431-4436. (doi:10.1210/en.2005-0195)

Kokay IC, Petersen SL \& Grattan DR 2011 Identification of prolactinsensitive GABA and kisspeptin neurons in regions of the rat hypothalamus involved in the control of fertility. Endocrinology 152 526-535. (doi:10.1210/en.2010-0668)

Kotani M, Detheux M, Vandenbogaerde A, Communi D, Vanderwinden JM, Le Poul E, Brézillon S, Tyldesley R, Suarez-Huerta N, Vandeput F et al. 2001 The metastasis suppressor gene KiSS-1 encodes kisspeptins, the natural ligands of the orphan $\mathrm{G}$ protein-coupled receptor GPR54. Journal of Biological Chemistry 276 34631-34636. (doi:10.1074/jbc. M104847200)

Li C, Chen P \& Smith MS 1998 The acute suckling stimulus induces expression of neuropeptide Y (NPY) in cells in the dorsomedial hypothalamus and increases NPY expression in the arcuate nucleus. Endocrinology 139 1645-1652. (doi:10.1210/endo.139.4.5905) 
Li C, Chen P \& Smith MS 1999 Neural populations in the rat forebrain and brainstem activated by the suckling stimulus as demonstrated by cFos expression. Neuroscience 94 117-129. (doi:10.1016/S0306-4522(99) 00236-5)

Li XF, Kinsey-Jones JS, Cheng Y, Knox AM, Lin Y, Petrou NA, Roseweir A, Lightman SL, Milligan SR, Millar RP et al. 2009 Kisspeptin signalling in the hypothalamic arcuate nucleus regulates $\mathrm{GnRH}$ pulse generator frequency in the rat. PLOS ONE 4 e8334. (doi:10.1371/journal.pone. 0008334)

Li Q, Rao A, Pereira A, Clarke IJ \& Smith JT 2011 Kisspeptin cells in the ovine arcuate nucleus express prolactin receptor but not melatonin receptor. Journal of Neuroendocrinology 23 871-882. (doi:10.1111/ j.1365-2826.2011.02195.x)

Liu X, Brown RS, Herbison AE \& Grattan DR 2014 Lactational anovulation in mice results from a selective loss of kisspeptin input to GnRH neurons. Endocrinology 155 193-203. (doi:10.1210/en.2013-1621)

Lonstein JS \& Stern JM 1999 Effects of unilateral suckling on nursing behavior and c-fos activity in the caudal periaqueductal gray in rats. Developmental Psychobiology 35 264-275. (doi:10.1002/(SICI) 1098-2302(199912)35:4\%3C;264::AID-DEV2\%3E;3.0.CO;2-U)

Maeda K, Tsukamura H \& Yokoyama A 1987 Suppression of luteinizing hormone secretion is removed at late lactation in ovariectomized lactating rats. Endocrinologia Japonica 34 709-716. (doi:10.1507/ endocrj1954.34.709)

Maeda KI, Tsukamura H, Uchida E, Ohkura N, Ohkura S \& Yokoyama A 1989 Changes in the pulsatile secretion of LH after the removal of and subsequent resuckling by pups in ovariectomized lactating rats. Journal of Endocrinology 121 277-283. (doi:10.1677/joe.0.1210277)

Marina N, Morales T, Díaz N \& Mena F 2002 Suckling-induced activation of neural c-fos expression at lower thoracic rat spinal cord segments. Brain Research 954 100-114. (doi:10.1016/S0006-8993(02)03349-8)

Mattheij JA, Swarts HJ \& Verstijnen CP 1984 The response of plasma prolactin to suckling during normal and prolonged lactation in the rat. Hormone Research 20 261-268. (doi:10.1159/000180006)

McNeilly AS 2001 Lactational control of reproduction. Reproduction, Fertility, and Development 13 583-590. (doi:10.1071/RD01056)

Overgaard A, Tena-Sempere M, Franceschini I, Desroziers E, Simonneaux V \& Mikkelsen JD 2013 Comparative analysis of kisspeptinimmunoreactivity reveals genuine differences in the hypothalamic Kiss1 systems between rats and mice. Peptides 45 85-90. (doi:10.1016/ j.peptides.2013.04.013)

Sawai N, Iijima N, Takumi K, Matsumoto K \& Ozawa H 2012 Immunofluorescent histochemical and ultrastructural studies on the innervation of kisspeptin/neurokinin B neurons to tuberoinfundibular dopaminergic neurons in the arcuate nucleus of rats. Neuroscience Research 74 10-16. (doi:10.1016/j.neures.2012.05.011)

Smith JT 2008 Kisspeptin signalling in the brain: steroid regulation in the rodent and ewe. Brain Research Reviews 57 288-298. (doi:10.1016/j. brainresrev.2007.04.002)

Smith MS \& Neill JD 1977 Inhibition of gonadotropin secretion during lactation in the rat: relative contribution of suckling and ovarian steroids. Biology of Reproduction 17 255-261. (doi:10.1095/biolreprod17. 2.255)

Smith JT, Popa SM, Clifton DK, Hoffman GE \& Steiner RA 2006a Kiss1 neurons in the forebrain as central processors for generating the preovulatory luteinizing hormone surge. Journal of Neuroscience $\mathbf{2 6}$ 6687-6694. (doi:10.1523/JNEUROSCI.1618-06.2006)

Smith JT, Acohido BV, Clifton DK \& Steiner RA 2006b KiSS-1 neurones are direct targets for leptin in the ob/ob mouse. Journal of Neuroendocrinology 18 298-303. (doi:10.1111/j.1365-2826.2006.01417.x)

Sonigo C, Bouilly J, Carré N, Tolle V, Caraty A, Tello J, Simony-Conesa FJ, Millar R, Young J \& Binart N 2012 Hyperprolactinemia-induced ovarian acyclicity is reversed by kisspeptin administration. Journal of Clinical Investigation 122 3791-3795. (doi:10.1172/JCI63937)

Szabo FK, Snyder N, Usdin TB \& Hoffman GE 2010 A direct neuronal connection between the subparafascicular and ventrolateral arcuate nuclei in non-lactating female rats. Could this pathway play a role in the suckling-induced prolactin release? Endocrine 37 62-70. (doi:10.1007/s12020-009-9266-z)

Szawka RE, Ribeiro AB, Leite CM, Helena CV, Franci CR, Anderson GM, Hoffman GE \& Anselmo-Franci JA 2010 Kisspeptin regulates prolactin release through hypothalamic dopaminergic neurons. Endocrinology 151 3247-3257. (doi:10.1210/en.2009-1414)

Takumi K, Iijima N, Higo S \& Ozawa H 2012 Immunohistochemical analysis of the colocalization of corticotropin-releasing hormone receptor and glucocorticoid receptor in kisspeptin neurons in the hypothalamus of female rats. Neuroscience Letters $53140-45$. (doi:10.1016/j.neulet.2012.10.010)

Terao Y, Kumano S, Takatsu Y, Hattori M, Nishimura A, Ohtaki T \& Shintani Y 2004 Expression of KiSS-1, a metastasis suppressor gene, in trophoblast giant cells of the rat placenta. Biochimica et Biophysica Acta 1678 102-110. (doi:10.1016/j.bbaexp.2004.02.005)

True C, Kirigiti M, Ciofi P, Grove KL \& Smith MS 2011 Characterisation of arcuate nucleus kisspeptin/neurokinin B neuronal projections and regulation during lactation in the rat. Journal of Neuroendocrinology $\mathbf{2 3}$ 52-64. (doi:10.1111/j.1365-2826.2010.02076.x)

True C, Verma S, Grove KL \& Smith MS 2013 Cocaine- and amphetamineregulated transcript is a potent stimulator of $\mathrm{GnRH}$ and kisspeptin cells and may contribute to negative energy balance-induced reproductive inhibition in females. Endocrinology 154 2821-2832. (doi:10.1210/en. 2013-1156)

Williams WP, Jarjisian SG, Mikkelsen JD \& Kriegsfeld LJ 2011 Circadian control of kisspeptin and a gated GnRH response mediate the preovulatory luteinizing hormone surge. Endocrinology 152 595-606. (doi:10.1210/en.2010-0943)

Yamada S, Uenoyama Y, Kinoshita M, Iwata K, Takase K, Matsui H, Adachi S, Inoue K, Maeda KI \& Tsukamura H 2007 Inhibition of metastin (kisspeptin-54)-GPR54 signaling in the arcuate nucleus-median eminence region during lactation in rats. Endocrinology 148 2226-2232. (doi:10.1210/en.2006-1529)

Yamada S, Uenoyama Y, Deura C, Minabe S, Naniwa Y, Iwata K, Kawata M, Maeda KI \& Tsukamura H 2012 Oestrogen-dependent suppression of pulsatile luteinising hormone secretion and kiss1 mRNA expression in the arcuate nucleus during late lactation in rats. Journal of Neuroendocrinology 24 1234-1242. (doi:10.1111/j.1365-2826.2012.02330.x)

Zhang C, Tonsfeldt KJ, Qiu J, Bosch MA, Kobayashi K, Steiner RA, Kelly MJ \& Rønnekleiv OK 2013 Molecular mechanisms that drive estradiol-dependent burst firing of Kiss1 neurons in the rostral periventricular preoptic area. American Journal of Physiology. Endocrinology and Metabolism 305 E1384-E1397. (doi:10.1152/ajpendo. 00406.2013)

Received in final form 2 September 2015

Accepted 9 September 2015

Accepted Preprint published online 9 September 2015 http://joe.endocrinology-journals.org

DOI: 10.1530/JOE-15-0143
๑) 2015 Society for Endocrinology Printed in Great Britain
Published by Bioscientifica Ltd. 